\title{
A formação docente em programas de pós-graduação em Engenharia de uma universidade federal brasileira: diagnóstico e perspectivas
}

\section{The teacher education in graduate programs in Engineering of a Brazilian federal university: diagnosis and perspectives}

\section{Formación docente en programas de postgrado en Ingeniería de una universidad pública brasileña: diagnóstico y perspectivas}

http://dx.doi.org/10.221713/2358-2332.2016.v14.14501

Dirléia dos Santos Lima, mestre em Engenharia Química pela Universidade Federal do Rio Grande do Sul (UFRGS), Porto Alegre, RS, Brasil. E-mail: dirlelima@gmail.com.

Luciano Andreatta Carvalho da Costa, doutor em Engenharia Civil pela Universidade Federal do Rio Grande do Sul (UFRGS), professor adjunto da Universidade Estadual do Rio Grande do Sul (UERGS), Porto Alegre, RS, Brasil. E-mail: andreatta.luciano@gmail.com.

\section{Resumo}

Neste trabalho, foi investigada a formação docente na pós-graduação stricto sensu em Engenharia. Como suporte teórico, o artigo recorreu aos autores que tratam do tema da Educação em Engenharia e às reflexões acerca do fazer docente da área. A pesquisa é quantitativa de natureza aplicada, caracterizada como exploratória, e foi realizada com alunos dos programas de pós-graduação em Engenharia de uma universidade federal. Acima de $40 \%$ dos pós-graduandos que responderam o questionário têm interesse na carreira docente, mas a preparação específica para o exercício da docência é quase inexistente nos cursos que realizam, apenas se atrelando ao estágio de docência que, para mais de $60 \%$ dos respondentes, é insuficiente. Por isso, faz-se necessário que os programas de pós-graduação pensem na inclusão, em suas grades curriculares, de disciplinas que ofereçam uma formação didático-pedagógica, possibilitando àqueles que têm interesse em seguir na carreira acadêmica uma formação docente consistente.

Palavras-chave: Formação Docente. Docente-Engenheiro. Pós-Graduação em Engenharia. Docência na Engenharia.

\section{Abstract}

In this work the teacher education in Engineering graduate programs was investigated. As a theoretical support, authors who deal with the theme of Engineering

\footnotetext{
${ }^{1}$ Como citar: ABNT NBR 6023:2002 e incluir o DOI.
} 
Lima e Costa / A formação docente em programas de pós-graduação em Engenharia de uma universidade federal brasileira: diagnóstico e perspectivas

Education, and their reflections on teaching this subject were used. It was a quantitative research of applied nature, characterized as exploratory, carried out with students of the Engineering graduate program of a federal university. Over $40 \%$ of the graduate students who answered the survey are interested in the teaching career, though specific preparation for teaching is almost inexistent in the courses they attend, except for the teaching internship, which is deemed insufficient by more than $60 \%$ of the respondents. Therefore, it is advised that graduate programs consider the inclusion of courses that offer didacticalpedagogical training in their curricular structures, thus enabling a consistent educational formation for those students who have an interest in following the academic career.

Keywords: Teacher Education. Teacher-Engineer. Engineering Graduate Studies. Teaching in Engineering.

\section{Resumen}

Este trabajo analiza la formación docente en el postgrado stricto sensu en Ingeniería. Para la metodología teórica, se recurrió a autores que estudian la Educación en Ingeniería y sus reflexiones acerca del hacer docente en el área. Se trató de una investigación cuantitativa de naturaleza aplicada, caracterizada como exploratoria, llevada a cabo con alumnos de los programas de postgrado en Ingeniería de una universidad pública de Brasil. Más del $40 \%$ de los estudiantes de postgrado que respondieron a la encuesta tienen interés en la carrera docente, pero consideran casi inexistente la preparación específica para el ejercicio de la docencia durante las clases, y dependen solo de las prácticas obligatorias de docencia que, para más del $60 \%$ de los encuestados, son insuficientes. Para ello, los programas de postgrado deben incluir en el plan de estudios asignaturas que les ofrezcan a los interesados en seguir en la carrera académica una formación didáctico-pedagógica más consistente.

Palabras clave: Formación Docente. Docente-Ingeniero. Postgrado en Ingeniería. Docencia en Ingeniería.

\section{INTRODUÇÃO}

Nos últimos anos vem crescendo, cada vez mais, o interesse dos estudiosos da área de Educação sobre a questão da docência e os aspectos envolvidos no desenvolvimento dessa atividade profissional. O termo docência tem sua origem da palavra latina docere, que significa ensinar, e sua ação é complementada pela palavra discere, que significa aprender. Assim, a docência, entendida como o exercício do magistério voltado para a aprendizagem, é a atividade que caracteriza o docente em geral. No ensino superior, as principais atividades do professor universitário se constituem pela docência em conjunto com a pesquisa (PEREIRA et al., 2012). A preparação do docente, as habilidades e as competências necessárias para o exercício da profissão são assuntos muito estudados por aqueles que buscam uma melhora no sistema educacional. 
Lima e Costa / A formação docente em programas de pós-graduação em Engenharia de uma universidade federal brasileira: diagnóstico e perspectivas

Atualmente, publicam-se diversos trabalhos relacionados à Educação em Engenharia, apresentando o panorama atual dessa parcela do ensino superior (CUNHA, 2009; OLIVEIRA et al., 2013; PEREIRA et al., 2012). Esses estudos abordam a formação do docente-engenheiro, os tipos de metodologias utilizadas para o trabalho em sala de aula e, alguns, o foco sobre a visão do aluno. Neste caso, tratam-se das características consideradas necessárias ao "bom professor". Este é um tema que preocupa bastante, pois a deficiência na formação dos professores universitários pode trazer implicações negativas para o processo de ensino-aprendizagem e para o desempenho da profissão docente, gerando dificuldades para o cumprimento do papel (PEREIRA; ANJOS, 2014). Por isso, a problematização dessa questão parte da premissa de que os professores universitários não possuem capacitação específica para as atividades docentes nesse nível de ensino, sendo que a experiência profissional docente e a titulação acadêmica não eram as exigências mais importantes para o ingresso nessa carreira, até recentemente (SILVEIRA, 2001).

Os docentes da Engenharia eram profissionais que atuavam no mercado de trabalho e exerciam a docência, muitas vezes, por hobby ou por ter espírito altruísta, sem ter um compromisso com a regência. Em geral, para se tornar docente, bastava ser bom aluno de graduação e se interessar pelo exercício do magistério, restando ao "novo" professor, sem formação pedagógica, começar a reproduzir os caminhos que fez na própria formação em Engenharia e se constituir docente pela experiência desenvolvida no decorrer do exercício profissional (DANTAS, 2014).

Com o passar dos anos, a profissão acadêmica, em especial quando exercida em instituições públicas, foi ganhando importância, passando a ser valorizada no mercado de trabalho. A partir de então, muitos docentes que tinham como principal atividade a sua atuação na indústria acabaram por dar preferência às funções que exerciam nas instituições de educação superior (IES), principalmente devido à primazia dada à dedicação exclusiva e ao incentivo ao desenvolvimento de pesquisas. Esse conjunto de mudanças, paralelamente à criação da pós-graduação, fez com que o perfil do professor universitário fosse alterado significativamente. O professor que visava se especializar apenas na sua área de formação inicial, que originou sua dissertação ou tese - por exemplo, em Engenharia Química ou Engenharia Civil - na organização atual, tem dado lugar a um profissional que tem investido no ensino, instigando seus alunos a compreender e a participar do processo de ensino e aprendizagem (DANTAS, 2011). Por isso, na atualidade, vivenciamos um cenário distinto do anterior. Hoje a titulação de mestre ou doutor, na maioria dos casos, tornou-se um requisito para atuação como professor, no entanto, a formação para o exercício do magistério continua praticamente inexistente (PINTO; OLIVEIRA, 2012).

No trabalho desenvolvido por Laudares (2010), que teve como objeto de pesquisa a descoberta do exercício docente por engenheiros que passaram a atuar também como professores, foi constatado que a formação prévia para o ingresso no magistério é quase inexistente. Dos 11 entrevistados, apenas dois a possuíam na modalidade de licenciatura 
Lima e Costa / A formação docente em programas de pós-graduação em Engenharia de uma universidade federal brasileira: diagnóstico e perspectivas

e declararam que, após já estarem trabalhando como docentes, buscaram complementação por meio de cursos de curta duração ofertados pela instituição empregadora.

A falta de capacitação para o exercício docente nos cursos de mestrado e doutorado em Engenharia pode estar relacionada ao fato de que uma boa parte dos pósgraduandos não tem interesse em seguir a carreira docente após a obtenção do título. Existe, também, uma falta de investimento na carreira docente durante a pós-graduação. Um exemplo disso é a implantação tardia do estágio de docência, que somente em 2002 se tornou obrigatório para os bolsistas do Programa de Demanda Social da Coordenação de Aperfeiçoamento de Pessoal de Nível Superior (Capes) como parte integrante de sua formação. De acordo com o artigo 17 do anexo da Portaria Capes $N^{\circ}$ 52/2002, a duração mínima do estágio de docência deve ser de um semestre para o mestrado e dois semestres para o doutorado, visando à preparação para a docência e a qualificação do ensino de graduação (COORDENAÇÃO DE APERFEIÇOAMENTO DE PESSOAL DE NÍVEL SUPERIOR, 2010).

Devido às poucas opções de formação, ficam reduzidas as oportunidades de adquirir conhecimento e experiência na prática pedagógica, prejudicando assim aqueles que têm interesse em seguir na docência (DWEK; MOTTA; THIOLLENT, 2015). Para agravar ainda mais este quadro, o amplo acesso à informação que se tem nos dias de hoje impõe novos desafios ao professor, como: formação continuada, adaptação a mudanças tecnológicas cada vez mais frequentes (há 15 anos, não se pensava na ideia de disponibilizar conteúdos por meio de smartphones, por exemplo), capacidade de trabalhar em equipe e em projetos de cooperação local, nacional e internacional, iniciativa e "capacidade de produzir conhecimento e tecnologia para desempenhar sua profissão de forma contextualizada" (DANTAS, 2011, p. 45).

Dentro desse contexto, este estudo tem como objetivo analisar como estão se saindo os egressos dos cursos de pós-graduação em Engenharia quanto à preparação para o exercício da docência e levantar a discussão sobre a importância de buscar uma formação didático-pedagógica que prepare o professor, e não somente o engenheiro, para o exercício da profissão.

\section{METODOLOGIA}

O trabalho consiste em uma pesquisa quantitativa de natureza aplicada, caracterizada como exploratória. Quanto aos procedimentos, utilizou-se o método de pesquisa adotado para levantamentos de dados, denominado survey (BABBIE, 2001). Surveys se diferenciam dos censos, pois, essencialmente, consultam apenas uma amostra da população. Este método busca informação diretamente com um grupo de interesse a respeito dos dados que se deseja obter. Trata-se, portanto, de um procedimento útil, especialmente em pesquisas exploratórias e descritivas. Oliveira e Vieira (2010) utilizaram a pesquisa do tipo survey para mapear o trabalho docente na educação básica no Brasil. Este método capta dados ou informações sobre as características delimitadas, assim como é possível coletar as opiniões de determinado grupo de pessoas, indicando 
Lima e Costa / A formação docente em programas de pós-graduação em Engenharia de uma universidade federal brasileira: diagnóstico e perspectivas

uma população-alvo. Nesse tipo de pesquisa, um questionário é utilizado como instrumento, em que o respondente não é identificável, garantindo o sigilo sobre o participante (SILVEIRA; CÓRDOVA, 2009).

A pesquisa foi realizada com os alunos matriculados em programas de pósgraduação em Engenharia Civil, Engenharia Elétrica, Engenharia Mecânica e Engenharia Química de uma instituição federal localizada no estado do Rio Grande do Sul. A aplicação da pesquisa foi feita de forma on-line, por meio de uma enquete com perguntas fechadas, em que se utilizou a escala de Likert, com o objetivo de verificar o interesse desses pós-graduandos na carreira docente e a forma de preparação para seguir essa profissão. Para isso, os respondentes foram arguidos quanto ao seu interesse pela pósgraduação, ao exercício do magistério e à eficiência do estágio de docência.

Os resultados obtidos são exploratórios, pois correspondem a uma amostra composta de 73 questionários, representando $9 \%$ do total de alunos matriculados nos programas de pós-graduação, que são objeto deste estudo.

\section{RESULTADOS E DISCUSSÃO}

As Figuras 1 e 2 trazem os resultados que correspondem às respostas para as perguntas iniciais feitas no questionário, buscando saber um pouco sobre o interesse do pós-graduando quanto à carreira docente.

Analisando os resultados apresentados na Figura 1, referentes à questão: "qual o motivo que o levou a fazer um curso de pós-graduação em Engenharia?", observa-se que aproximadamente $40 \%$ dos respondentes informaram o interesse pela docência. Neste percentual soma-se o grupo dos que responderam se interessarem apenas pela docência com o grupo dos que buscavam realizar também pesquisa na atuação profissional. Esse número se deve principalmente ao fato de que, no cenário atual, para ingressar como docente no ensino superior, os títulos de mestre ou doutor estão sendo cada vez mais exigidos como requisitos. Mesmo quando a vaga apresenta como critério mínimo apenas a graduação, a indicação de uma pós-graduação no currículo se torna um complemento positivo na disputa com os demais concorrentes. Ainda, compondo os $40 \%$, estão aqueles profissionais que ingressaram na pós-graduação visando à carreira docente e buscam, além da especialização em uma área de conhecimento, um suporte didático-pedagógico por acreditarem ser necessário para o exercício dessa função.

Os resultados obtidos para a pergunta: "você já possui alguma formação pedagógica?", apresentados na Figura 2, revelam um quadro bem comum nos cursos de pós-graduação stricto sensu nas instituições brasileiras - em especial no campo das Engenharias - pois apenas pouco mais de $10 \%$ dos respondentes possuem formação pedagógica e aproximadamente $2 \%$ estão com a formação em curso. Se analisarmos as respostas obtidas para essa questão, somente para o grupo de entrevistados que manifestou interesse na carreira docente (representando 40\% do total na Figura 1), o percentual daqueles que têm ou estão cursando uma formação pedagógica sobe para 
Lima e Costa / A formação docente em programas de pós-graduação em Engenharia de uma universidade federal brasileira: diagnóstico e perspectivas

19,2\%. Mesmo assim, esse resultado chama a atenção, pois, hoje em dia, são os egressos da pós-graduação que passam a integrar o corpo docente do ensino superior.

Figura 1 - Abordagem sobre o interesse em cursar uma pós-graduação em
Engenharia

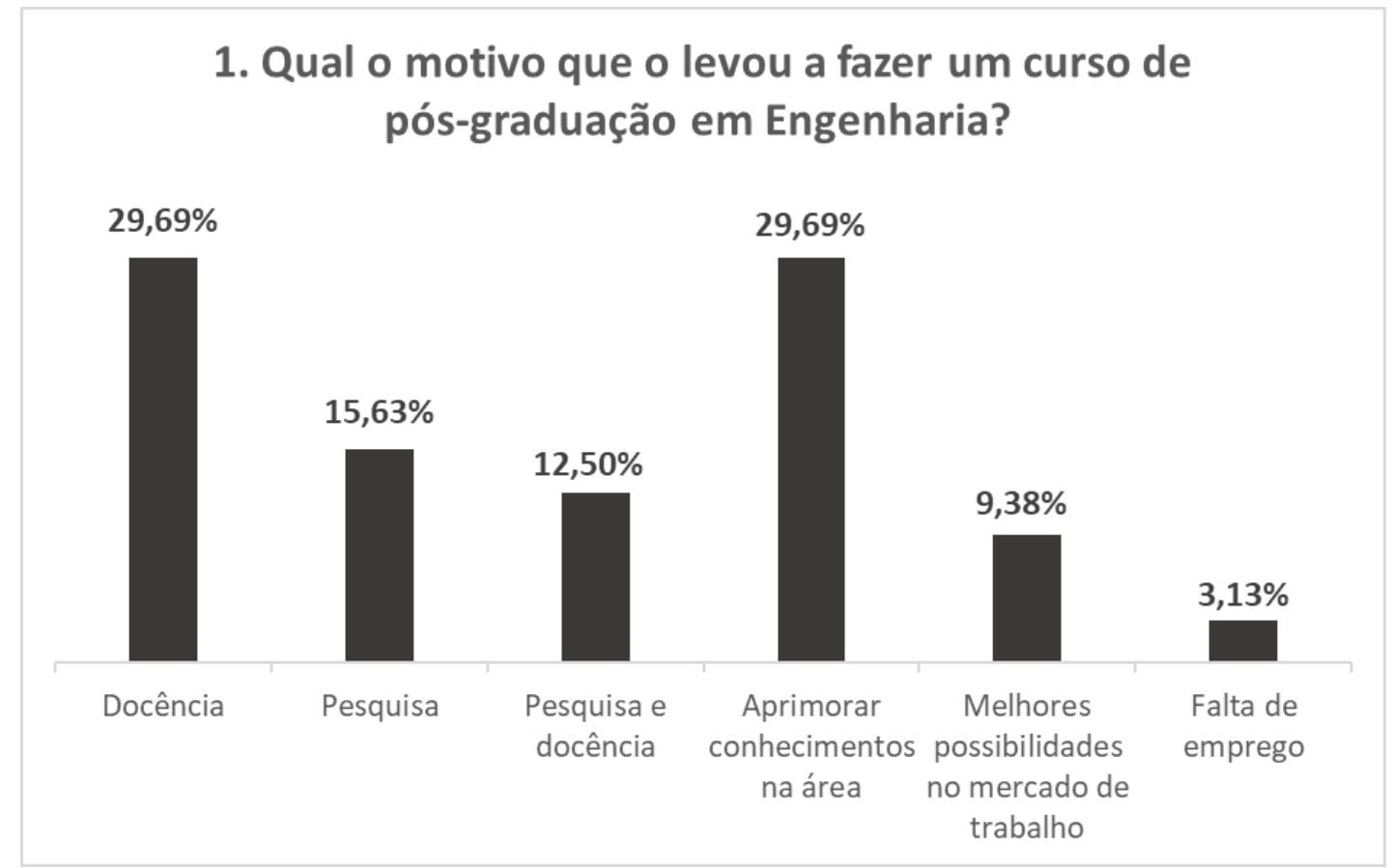

Fonte: Elaboração própria.

Pensar que apenas 19,2\% buscaram ou estão buscando uma formação pedagógica para exercer a função de formadores de outros profissionais reforça a discussão de outros trabalhos da literatura quanto à importância dada à formação pedagógica para atuação na carreira docente (LAUDARES, 2010; MATOS; IAOCHITE, 2013; REIS, 2008). A ideia de que "ensinar se aprende ensinando" sustentada apenas na experiência não é válida e reflete a visão nada profissional de que não é preciso se preparar para ser docente. Assim, como em outras profissões, a docência requer muita dedicação e capacitação para seu exercício. Hoje, para atuar no magistério adequadamente, são necessários conhecimentos específicos da área de docência. (DANTAS, 2011). Isso é também enfatizado por Cunha (2009), quando afirma que o magistério é uma atividade complexa que exige tanto uma preparação cuidadosa como singulares condições de exercício. 
Lima e Costa / A formação docente em programas de pós-graduação em Engenharia de uma universidade federal brasileira: diagnóstico e perspectivas

\section{Figura 2 - Abordagem sobre a existência de formação pedagógica}

\section{Você já possui alguma formação pedagógica?}

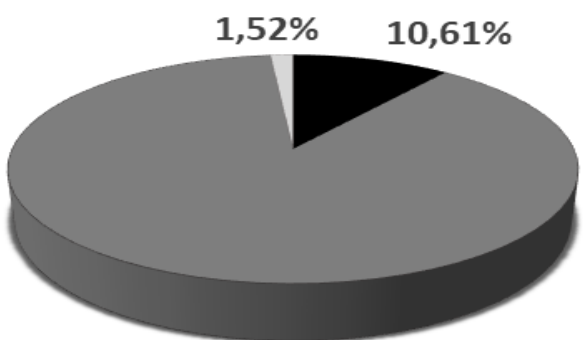

$87,88 \%$

Sim $\square$ Não $\square$ Emandamento

Fonte: Elaboração própria.

A Tabela 1 apresenta os questionamentos que foram feitos utilizando a escala de Likert para que os perguntados pudessem especificar seu nível de concordância com cada uma das afirmações feitas e, também, com os resultados obtidos.

Tabela 1 - Distribuição das respostas por nível de concordância, conforme a escala de Likert

\begin{tabular}{|c|c|c|c|c|c|}
\hline \multirow[b]{2}{*}{ Questionamentos } & \multicolumn{5}{|c|}{ Resultados } \\
\hline & $\begin{array}{l}\text { Concordo } \\
\text { totalmente }\end{array}$ & Concordo & Indiferente & Discordo & $\begin{array}{c}\text { Discordo } \\
\text { totalmente }\end{array}$ \\
\hline $\begin{array}{l}\text { 1. A formação inicial para a docência no ensino } \\
\text { superior, nos moldes como vem sendo praticada } \\
\text { nos programas de pós-graduação stricto sensu em } \\
\text { Engenharia, restringe-se à aquisição de } \\
\text { habilidades enquanto pesquisador na respectiva } \\
\text { área de conhecimento de cada programa. }\end{array}$ & $38,36 \%$ & $45,21 \%$ & $2,74 \%$ & $13,70 \%$ & $0,00 \%$ \\
\hline $\begin{array}{l}\text { 2. A forma como a disciplina de estágio de } \\
\text { docência é aplicada em meu curso de pós- } \\
\text { graduação cumpre seu papel para que eu me sinta } \\
\text { preparado para exercer a carreira docente. }\end{array}$ & $2,74 \%$ & $15,07 \%$ & $20,55 \%$ & $35,62 \%$ & $26,03 \%$ \\
\hline $\begin{array}{l}\text { 3. O estágio docente, da forma como vem sendo } \\
\text { realizado, proporciona um momento essencial } \\
\text { para que eu possa fazer a conexão entre teoria e } \\
\text { prática, tornando-se atividade relevante no que } \\
\text { diz respeito ao desenvolvimento de competências } \\
\text { indispensáveis à atuação pedagógica. }\end{array}$ & $12,50 \%$ & $30,56 \%$ & $16,67 \%$ & $26,39 \%$ & $13,89 \%$ \\
\hline $\begin{array}{l}\text { 4. Na primeira vez que estive em sala de aula } \\
\text { como ministrante, seja durante o estágio de } \\
\text { docência ou em outra oportunidade, sentia-me } \\
\text { bem preparado. }\end{array}$ & $4,11 \%$ & $24,66 \%$ & $16,44 \%$ & $39,73 \%$ & $15,07 \%$ \\
\hline $\begin{array}{l}\text { 5. Quando preciso ministrar uma aula procuro } \\
\text { apoiar-me em minha intuição ou modelos de } \\
\text { docentes que tive durante minha trajetória como } \\
\text { estudante. }\end{array}$ & $23,29 \%$ & $58,90 \%$ & $8,22 \%$ & $8,22 \%$ & $1,37 \%$ \\
\hline
\end{tabular}


Lima e Costa / A formação docente em programas de pós-graduação em Engenharia de uma universidade federal brasileira: diagnóstico e perspectivas

\begin{tabular}{|c|c|c|c|c|c|}
\hline $\begin{array}{l}\text { 6. Acredito que a docência, assim como a } \\
\text { pesquisa ou qualquer outra atividade profissional, } \\
\text { exige uma capacitação específica. }\end{array}$ & $34,25 \%$ & $50,68 \%$ & $6,85 \%$ & $6,85 \%$ & $1,37 \%$ \\
\hline $\begin{array}{l}\text { 7. Os saberes das áreas de conhecimento são de } \\
\text { fundamental importância, mas não são suficientes } \\
\text { para o exercício da profissão de professor. É } \\
\text { preciso haver a integração entre o saber do } \\
\text { conteúdo a ser ensinado com os saberes didáticos } \\
\text { e pedagógicos. }\end{array}$ & $41,10 \%$ & $49,32 \%$ & $2,74 \%$ & $4,11 \%$ & $2,74 \%$ \\
\hline $\begin{array}{l}\text { 8. Quanto à função docente, acredito que o } \\
\text { conhecimento se estabelece a partir da ação do } \\
\text { aluno ao longo do processo ensino- } \\
\text { aprendizagem. }\end{array}$ & $6,85 \%$ & $68,49 \%$ & $10,96 \%$ & $10,96 \%$ & $2,74 \%$ \\
\hline $\begin{array}{l}\text { 9. No exercício docente, deve ser priorizada a } \\
\text { exposição de conteúdos, pois o professor é quem } \\
\text { domina o assunto a ser trabalhado. }\end{array}$ & $4,17 \%$ & $34,72 \%$ & $19,44 \%$ & $37,50 \%$ & $4,17 \%$ \\
\hline
\end{tabular}

Fonte: Elaboração própria.

Pela Tabela 1, analisando as respostas para a assertiva 1, em que $83,57 \%$ dos respondentes concordaram com a afirmação feita, torna-se evidente que os pósgraduandos têm consciência de que essa formação deixa os egressos melhor preparados para serem pesquisadores do que docentes. Esse resultado se justifica pelo percurso traçado durante a pós-graduação stricto sensu. Após o ingresso, são cursadas disciplinas específicas da área e o acadêmico passa a integrar uma linha de pesquisa dentro da qual desenvolverá seu trabalho como pesquisador afim de, no final desse caminho, receber sua titulação de mestre ou doutor. Durante esse período, os únicos momentos de preparação para o magistério ficam restritos aos estágios de docência, obrigatórios para os beneficiários de bolsas Capes, como parte integrante de sua formação. Esse cenário é o mesmo apresentado no trabalho de Soares e Cunha (2010), onde é dito que, como os programas centram suas energias na formação para pesquisa, assume-se a posição de que os saberes da investigação se transformam, automaticamente, em saberes da docência e são suficientes para o exercício do magistério.

Pelo retorno obtido da assertiva 2, em que $61,65 \%$ dos respondentes discordaram, nota-se a pouca eficiência que a disciplina de estágio de docência tem na formação dos futuros professores-engenheiros. Analisando somente as respostas daqueles que têm interesse no exercício do magistério, o percentual dos que discordam cai para 53,33\%, mas, ainda assim, é um resultado expressivo que demonstra ser fundamental um melhor planejamento dos estágios de docência para que estes atinjam o objetivo de dar suporte ao desenvolvimento das competências necessárias aos futuros docentes.

Esse resultado está de acordo com o trabalho publicado por Magalhães et al. (2016), onde é dito que a formação para a docência no ensino superior não se resume a um curso introdutório e a uma experiência de docência assistida. Ainda, neste trabalho, são apresentadas informações sobre a criação de encontros com objetivos de sistematizar processos de ensino e aprendizagem, assentadas em conteúdos das áreas de domínio dos pós-graduandos. Esses encontros se caracterizam por serem aulas presenciais elaboradas 
Lima e Costa / A formação docente em programas de pós-graduação em Engenharia de uma universidade federal brasileira: diagnóstico e perspectivas

em formato que articulam reflexão e prática, garantindo um momento propício para que aqueles que têm interesse na carreira docente possam desenvolver suas capacidades.

Já pela assertiva 3, houve um equilíbrio entre os que concordaram e os que discordaram, pois $43,06 \%$ responderam positivamente, enquanto $40,28 \%$ responderam negativamente à afirmativa. Isso se deve, possivelmente, ao fato de que os $43,06 \%$ que concordaram com a afirmação encaram o estágio de docência como a única oportunidade que têm para desenvolver suas competências pedagógicas, por isso o consideram essencial em sua formação. Já os 40,28\% que discordaram têm consciência de que o estágio docente, devido à curta duração, falta de supervisão e troca de experiências não possibilita o aperfeiçoamento de competências suficientes para exercer o magistério. Segundo Campelo et al. (2010), durante a realização das atividades do estágio-docência, essa troca de experiências é válida para que ocorra o desenvolvimento das habilidades necessárias à carreira docente.

A necessidade de disciplinas específicas, voltadas para a docência, nos programas de pós-graduação em Engenharia ficou evidente pelas respostas à afirmativa 4, pois mais da metade dos sujeitos pesquisados $(54,8 \%)$ manifestou-se negativamente. Ou seja, eles não se sentiam bem preparados. Isso ocorre porque já se sabe que a preparação para atuar em sala de aula vai muito além do conhecimento dos temas que serão abordados. O professor tem o papel de levar o aluno ao entendimento de algo novo e, para isso, muitas vezes conhecer o assunto não é suficiente, é necessário dispor de ferramentas que facilitem o processo de ensino-aprendizagem.

A consequência da falta de preparação específica para o exercício da docência fica evidente nas respostas à assertiva 5, onde 82,19\% dos pós-graduandos concordaram que, quando são solicitados a ministrar aulas, procuram se apoiar na intuição ou nos exemplos de professores que tiveram na sua trajetória estudantil. Esse alto nível de concordância reflete a falta de base didático-pedagógica necessária para se ter um domínio no planejamento de aulas e em sua execução. Com isso recaímos, na maioria dos casos, em aulas essencialmente expositivas que se tornam maçantes para os alunos dos cursos de graduação em Engenharia. Como solução, poderiam ser utilizadas alternativas pedagógicas, por exemplo, por meio da adoção da aplicação prática do conhecimento teórico, como a discutida no trabalho de Bressane et al. (2015). Os referidos autores indicam que esse tipo de conduta em sala de aula condiciona os alunos a uma postura ativa e engajada, possibilitando que eles exercitem habilidades técnicas e competências comportamentais.

A afirmativa 6 teve manifestação positiva de 84,95\% dos respondentes e está de acordo com o trabalho publicado por Masetto (2003). O autor afirma que recentemente os professores universitários começaram a tomar consciência de que o papel de docente do ensino superior, como de qualquer outra profissão, exige capacitação própria e específica que não se restringe a ter um diploma de bacharel ou de mestre ou de doutor, ou apenas o exercício da profissão. Além de tudo isso, requer-se também competência pedagógica dos professores, tendo em vista sua função de educador. Cabe destacar a 
Lima e Costa / A formação docente em programas de pós-graduação em Engenharia de uma universidade federal brasileira: diagnóstico e perspectivas

importância das instituições de ensino superior (IES) no desenvolvimento desses professores. Elas devem ser capazes de oferecer capacitação adequada ao futuro docente e fornecer formação continuada ao professor que está em exercício.

A necessidade de capacitação específica também foi abordada na assertiva 7, com a qual $90,42 \%$ dos respondentes concordaram, demonstrando que os futuros professores com formação em Engenharia sabem da sua necessidade de capacitação voltada especificamente para a carreira docente. Pois hoje, para exercê-la adequadamente, necessita-se muito mais que conhecimentos técnicos da área, além destes, são necessários conhecimentos específicos que fazem do professor não apenas um transmissor de conhecimento, mas um instigador que leva o aluno à construção de um conhecimento sólido e duradouro (DANTAS, 2011).

Reflexão semelhante é feita por Cunha (2009), quando declara que a docência é uma atividade complexa que exige tanto uma preparação cuidadosa como singulares condições para o exercício. Não sendo oferecida tal capacitação no programa de pósgraduação que realizam, seria razoável que os estudantes buscassem em outros programas, ou até mesmo em outras instituições, os ensinamentos almejados. Mas, provavelmente, devido à carga horária de disciplinas requerida nos cursos de Engenharia e à exigência de grande dedicação à pesquisa, na maioria das vezes, falta tempo para realização de atividades complementares. Desse modo, a capacitação à docência permanece em segundo plano. Surge assim a importância de serem redefinidos os quadros de disciplinas dos cursos de mestrado e de doutorado para que se tenha uma ampliação dos espaços para a preparação à docência como um dos eixos prioritários, possibilitando uma melhor articulação entre o ensino e a pesquisa (GERAB et al., 2014).

As assertivas 8 e 9 visam saber dos pós-graduandos o entendimento deles sobre o processo-ensino aprendizagem, visto que no futuro, para alguns bem próximo, estarão trabalhando nesse processo em suas salas de aula. A assertiva 8, "quanto à função docente, acredito que o conhecimento se estabelece a partir da ação do aluno ao longo do processo ensino-aprendizagem", teve um retorno positivo, pois $75,34 \%$ dos respondentes concordam com a afirmação, ou seja, entendem que é necessária uma ação do aluno para que o processo de aprendizagem ocorra. E como será possível que o aluno tenha essa ação, se não houver diálogo entre professor e aluno? Essa questão preocupa ainda mais quando comparada com os resultados obtidos para a afirmativa 9, "no exercício docente, deve ser priorizada a exposição de conteúdos, pois o professor é quem domina o assunto a ser trabalhado", em que a diferença entre os que concordam com a afirmação e aqueles que discordam foi mínima, 38,89\% e 41,67\%, respectivamente.

Esse resultado evidencia uma contradição, pois muitos que responderam que a ação do aluno é importante para a aprendizagem entendem que devem ser priorizadas as aulas expositivas. Segundo Franco (2012), já se sabe que a exposição de conteúdos não basta para que o aluno compreenda o ensinado, não por ser ruim, mas sim por ser insuficiente. Dessa forma, mais uma vez fica evidente a necessidade de uma preparação específica para docência que dê ao professor ferramentas para levar seu aluno à construção do 
Lima e Costa / A formação docente em programas de pós-graduação em Engenharia de uma universidade federal brasileira: diagnóstico e perspectivas

próprio conhecimento, pois ele dificilmente empreenderá uma docência que assuma o aluno como sujeito de sua aprendizagem se não estiver envolvido em contextos de partilha, de debates de ideias, de reconhecimento dos próprios limites e das possibilidades (GERAB et al., 2014). Um exemplo de uso de ferramentas para a construção de conhecimento foi apresentado no trabalho de Zanrosso et al. (2017), onde um grupo de engenheiras, cursando pós-graduação lato sensu em Educação em Engenharia, desenvolveram em aula um experimento bem simples, mas que ajudou os alunos a entenderem melhor os conceitos inerentes ao tema da aula, sendo que essa melhora foi identificada mediante aplicação de pré-teste e pós-teste em conjunto com o experimento. Essa busca por uma nova metodologia na abordagem dos assuntos, como a empregada no trabalho citado, que vise ganhos no processo de ensino-aprendizagem, deve estar sempre presente na vida dos futuros docentes e, também, após estarem atuantes na carreira.

Uma forma de possibilitar com que os pós-graduandos tenham um espaço para desenvolver capacidades intrínsecas à docência pode ser exemplificada pela iniciativa do Programa de Engenharia de Produção (PEP) do Instituto Alberto Luiz Coimbra de PósGraduação e Pesquisa da Universidade Federal do Rio de Janeiro (COPPE/UFRJ). Motivados pela ausência de requisitos pedagógicos, bem como pela carência de reflexão sobre questões ligadas ao ensino de Engenharia e inspirados pela disciplina de estágio de docência, alguns professores do programa organizaram uma série de 12 encontros para $o$ estudo e a discussão de assuntos ligados ao tema, reunidos em uma disciplina optativa chamada Seminários de Docência. Essa disciplina envolveu alunos tanto de mestrado quanto de doutorado, durante um trimestre - de setembro a dezembro de 2010. O objetivo dessa disciplina era estimular o contato com a prática docente, por meio de simulações de aula e do planejamento de uma disciplina da área, proporcionar aos alunos um espaço de discussão sobre aspectos inovadores e polêmicos do ensino de Engenharia e possibilitar que observassem, pela prática e pela reflexão, qual o mérito, a utilidade, as dificuldades e os inconvenientes de cada um deles.

Ainda em relação a essa iniciativa, outro anseio na preparação da disciplina era o de apresentar aos alunos as mais diversas ferramentas para aprimorar a dinâmica da educação científica e tecnológica. O resultado do que foi feito ficou evidente ao final da experiência, pois o saldo foi positivo, com o reconhecimento, por parte dos alunos, da importância de uma disciplina de preparação à prática docente nas escolas de Engenharia. Tornou-se claro que a docência é uma atividade que se aprende pela prática e pela reflexão sobre ela, sendo preciso disputar, dentro dos programas de pós-graduação, por um espaço para a formação e o aperfeiçoamento dos professores, valorizando o treinamento para esse ofício, tão subestimado quanto essencial (DWEK; MOTTA; THIOLLENT, 2015).

\section{CONSIDERAÇÕES FINAIS}

Este trabalho é resultado da preocupação dos autores com a formação docente durante a pós-graduação em Engenharia e teve como uma de suas motivações a experiência vivenciada por um deles. Partiu-se do senso comum de que o mestrado e o 
Lima e Costa / A formação docente em programas de pós-graduação em Engenharia de uma universidade federal brasileira: diagnóstico e perspectivas

doutorado, além de uma formação técnica mais específica e dos títulos necessários para o ingresso na docência em nível superior, também lhes dariam o suporte didáticopedagógico considerado tão necessário para atuação na docência. Mas, com base no próprio percurso e nas informações obtidas na pesquisa, verificou-se que foram poucos os momentos durante a pós-graduação que proporcionaram a oportunidade de refletir e praticar o exercício do magistério, ficando restritos aos estágios de docência que têm curta duração, levando a uma constatação da necessidade de uma formação específica para atuação na profissão docente.

A discussão do tema aqui abordado e a realização de trabalhos científicos que possam oferecer contribuições para o seu desenvolvimento são igualmente relevantes para a melhoria do ensino superior no país. Pois, majoritariamente, são os egressos de programas pós-graduação que futuramente estarão em sala de aula, formando novos profissionais para atuarem na sociedade.

Neste estudo, aproximadamente $40 \%$ dos respondentes têm interesse em seguir a carreira docente, mas os programas de pós-graduação em Engenharia não oferecem formação específica para o exercício da docência, apenas é exigida a realização do estágio de docência para aqueles que são beneficiários de bolsas da Capes. Nessas condições, somente $12 \%$ dos respondentes possuem ou estão com uma formação pedagógica em andamento - que, sobretudo, é realizada fora de seus PPG.

Os resultados obtidos são considerados exploratórios, pois o objeto de estudo permaneceu restrito a um pequeno grupo de discentes de uma única instituição. Ainda assim, as informações obtidas corroboram o debate sobre o tema evidenciando a necessidade de uma preparação mais voltada ao exercício da docência, uma vez que mais de $60 \%$ dos respondentes afirmam que o estágio de docência não é suficiente para preparar o pós-graduando para posterior atuação na carreira docente. Novos trabalhos, envolvendo um grupo amplo e também com a participação de outras instituições, são desejáveis para que se possa fazer um diagnóstico mais consistente do panorama atual.

Portanto, é necessário que esse tema continue a ser discutido e estudado para que, futuramente, os programas de pós-graduação em Engenharia repensem suas grades curriculares e incluam disciplinas voltadas à docência a fỉm de, juntamente com os estágios de docência, contribuir na formação didático-pedagógica daqueles que têm interesse em seguir a carreira acadêmica.

\section{Referências}

BABBIE, E. Métodos de Pesquisas de Survey. Belo Horizonte: Editora UFMG, 2001.

BRESSANE, A. et al. Abordagem construtivista integrando o ensino, a pesquisa e a aplicação à realidade: o caso da pós-graduação em Ciências Ambientais da Unesp Sorocaba. Revista Brasileira de Pós-Graduação, Brasília, DF, v. 12, n. 27, p. 251-276, 2015 . 
Lima e Costa / A formação docente em programas de pós-graduação em Engenharia de uma universidade federal brasileira: diagnóstico e perspectivas

CAMPELO, R. P. M. et al. Uma nova abordagem do estágio docência para Ciências Biológicas. Revista Brasileira de Pós-Graduação, Brasília, DF, v. 7, n. 14, p. 507-518, 2010.

\section{COORDENAÇÃO DE APERFEIÇOAMENTO DE PESSOAL DE NÍVEL}

SUPERIOR. Portaria ${ }^{\circ}$ 76, de 14 de abril de 2010. Diário Oficial da União, Brasília, DF, 19 abr. 2010. Seção 1, p. 31-32. Disponível em: 〈https://goo.gl/nVPoB〉. Acesso em: 1 mar. 2017.

CUNHA, M. I. O lugar da formação do professor universitário: o espaço da pósgraduação em educação em questão. Revista Diálogo Educacional, Curitiba, v. 9, n. 26, p. 81-90, 2009.

DANTAS, C. M. M. Docentes engenheiros e sua preparação didático-pedagógica. Revista de Ensino de Engenharia, Passo Fundo, v. 33, n. 2, p. 45-52, 2014.

O desenvolvimento da docência nas engenharias: um estudo na Universidade Federal de Campina Grande (UFCG). 2011. 122 f. Dissertação (Mestrado em Educação) - Universidade Federal do Rio Grande do Norte, Natal, 2011.

DWEK, M.; MOTTA, A. C. G. D.; THIOLLENT, M. J. M. Relato de experiência da disciplina "Seminários de Docência", do Programa de Engenharia de Produção da COPPE/UFRJ. Revista Docência do Ensino Superior, Belo Horizonte, v. 5, n. 1, p. 37 $66,2015$.

FRANCO, S. R. K.; Ensino e construção de conhecimento: é possível pensar o ensino de Engenharia como construção de conhecimento? In: COSTA, L. A.; NIETZKE, J. A. (Org.). A educação em Engenharia: fundamentos teóricos e possibilidades didáticopedagógicas. Porto Alegre: UFRGS Editora, 2012. p. 15-26.

GERAB, I. F. et al. Avaliação da disciplina Formação Didático-Pedagógica em Saúde: a ótica dos pós-graduandos. Revista Brasileira de Pós-Graduação, Brasília, DF, v. 11, n. 24, p. 533-552, 2014.

LAUDARES, J. B. A descoberta da docência por engenheiros-professores e suas representações. In: CONGRESSO BRASILEIRO DE ENSINO DE ENGENHARIA, 38., 2010, Fortaleza. Anais... Fortaleza: Universidade Federal do Ceará, 2010.

MAGALHÃES, R. C. B. P. et al. Formação docente na pós-graduação stricto sensu: experiências na Universidade Federal do Rio Grande do Norte. Revista Brasileira de Pós-Graduação, Brasília, DF, v. 13, n. 31, p. 559-582, 2016.

MASETTO, M. T. Competência pedagógica do professor universitário. São Paulo: Summus, 2003.

MATOS, M. M.; IAOCHITE, R. T. A formação do professor universitário do curso de engenharia: exploração inicial. In: CONGRESSO NACIONAL DE EDUCAÇÃO - 
Lima e Costa / A formação docente em programas de pós-graduação em Engenharia de uma universidade federal brasileira: diagnóstico e perspectivas

EDUCERE, 11., 2013, Curitiba. Anais... Curitiba: Pontifícia Universidade Católica do Paraná, 2013.

OLIVEIRA, H. B. et al. A dimensão pedagógica na formação de professores na pósgraduação dos cursos de física, engenharia mecânica e ciências da saúde da UFU e UMG.

História e Diversidade, Cáceres, v. 2, n. 1, p. 155-171, 2013.

OLIVEIRA, D. A.; VIEIRA, L. M. F. (Coord.). Sinopse do Survey Nacional: pesquisa trabalho docente na educação básica no Brasil. Belo Horizonte: Grupo de Estudos sobre Política Educacional e Trabalho Docente, 2010.

PEREIRA, T. R. D. S. et al. Professores engenheiros: processo de construção da prática pedagógica no curso de Engenharia de Produção Civil da Uneb. In: CONGRESSO BRASILEIRO DE ENSINO DE ENGENHARIA, 40., 2012, Belém. Anais... Belém: Universidade Federal do Pará, 2012.

PEREIRA, L. R.; ANJOS, D. D. O professor do ensino superior: perfil, desafios e trajetórias de formação. In: SEMINÁRIO INTERNACIONAL DE EDUCAÇÃO SUPERIOR - FORMAÇÃO E CONHECIMENTO, 2014, Sorocaba. Anais... Sorocaba: EdUniso, 2014.

PINTO, D. P.; OLIVEIRA, V. F. Reflexões sobre a prática do engenheiro-professor. In: CONGRESSO BRASILEIRO DE ENSINO DE ENGENHARIA, 40., 2012, Belém. Anais... Belém: Universidade Federal do Pará, 2012.

REIS, C. A. C. A formação do professor de engenharia. In: SEMINÁRIO NACIONAL DE EDUCAÇÃO PROFISSIONAL E TECNOLÓGICA, 1., 2008, Belo Horizonte. Anais... Belo Horizonte: Centro Federal de Educação Tecnológica de Minas Gerais, 2008.

SILVEIRA, M. H. Docência, educação e tecnologia: aproximações. In: ENCONTRO DE ENSINO DE ENGENHARIA, 7., 2001, Petrópolis. Anais... Petrópolis: Universidade Federal do Rio de Janeiro, 2001.

SILVEIRA, D. T.; CÓRDOVA, F. P. A pesquisa científica. In: GERHARDT, T. E.; SILVEIRA, D. T. (Org.). Métodos de pesquisa. Porto Alegre: UFRGS Editora, 2009. p. $31-42$.

SOARES, S. R.; CUNHA, M. I. Programas de pós-graduação em Educação: lugar de formação da docência universitária? Revista Brasileira de Pós-Graduação, Brasília, DF, v.7, n. 14, p. 577-604, 2010.

ZANROSSO, C. D. et al. Operação café passado: uma perspectiva didático-pedagógica para o ensino em engenharia química. Química Nova, São Paulo, v. 40, n. 8, p. 957-962, 2017. 